\title{
O ABRIGO E O EXÍLIO DE SÁ-CARNEIRO*
}

\section{Caio Gagliardi *}

\author{
Universidade de São Paulo
}

Resumo: Paris é um espaço-chave na poesia de Sá-Carneiro, não apenas por boa parte de seus poemas ter sido produzida ali, mas como realidade simbólica. Este artigo busca refletir a respeito do papel simbólico representado por Paris na obra do poeta Mário de Sá-Carneiro, tomando por base a análise do poema "Abrigo" (1915), sua abordagem comparativa com o poema "Memória", do poeta português António Nobre, e com a correspondência que o escritor estabeleceu com o amigo e colega de geração Fernando Pessoa. Transfigurada pela linguagem, Paris é aqui enfocada como espaço de identificação e de alteridade: ao mesmo tempo abrigo dos afetos represados num passado perdido e exílio interior num presente imaginário. Essa cidade de sonho, profusamente retratada tanto na correspondência quanto na literatura do autor, contrasta com uma realidade histórica grave e urgente. $\mathrm{O}$ poeta admite, afinal, que a sua Paris é um espaço de linguagem, produto de sua nostalgia imaginativa.

Palavras-chave: Mário de Sá-Carneiro. António Nobre. Exílio. Paris.

Em uma de suas mais importantes cartas, enviada a João Gaspar Simões a 11 de dezembro de 1931, Fernando Pessoa censura-lhe as ilações biográficas e psicológicas a respeito de si e de Mário de Sá-Carneiro, que o crítico presencista arrisca nos estudos publicados em Mistério da poesia (1931). Ao se referir ao amigo, Pessoa considera que a sua obra é atravessada por uma "íntima desumanidade, ou, melhor, inumanidade: não tem calor humano, nem ternura humana, excepto a introvertida." (PESSOA, 1999, p. 254) A motivação para isso, bem como para sua tendência narcisista, seria, nesse comentário psicanalítico de Pessoa, a perda da mãe quando Sá-Carneiro tinha apenas dois anos. Para além da validade dessa explicação, interessa-nos explorar, mais como traço poético do que psicológico, a

Esta obra está licenciada sob uma Creative Commons - Atribuição 4.0

\footnotetext{
* Este trabalho é a reformulação integral de parte de um artigo de minha autoria, a respeito do poeta António Nobre, publicado na, há muito extinta, revista Voz Lusíada (17). O convite para a atual publicação possibilitoume revisar completamente aquele estudo, em que Sá-Carneiro aparecia somente a título comparativo, alterando seu enfoque original, cortando e depurando muitas passagens, e complementando-as com informações e bibliografia de que não dispunha na época.

* Caio Gagliardi é professor da Universidade de São Paulo na área de Literatura Portuguesa desde 2008. É coordenador do Grupo de Pesquisa Estudos Pessoanos (http://estudospessoanos.fflch.usp.br/) e editor, entre outros volumes, de Mensagem (2007) e Teatro do Exxtase (2010). Mestre e Doutor pelo IEL - UNICAMP, realizou Pós-Doutorado no Dipartimento di Studi Europei, Americani e Interculturali da Università degli Studi di Roma "La Sapienza" (UNIROMA) e no Departamento de Teoria Literária e Literatura Comparada (USP). Email: <caiogagliardi@gmail.com>.
} 
ternura introvertida a que Pessoa faz menção.

Sá-Carneiro escreveu todos os seus poemas entre 1913 e 1916, a maior parte deles em Paris. Em 1914 saiu o seu primeiro livro de versos, Dispersão, em edição do autor, e apenas em 1937, vinte e um anos após a sua morte, portanto, a Editorial Presença publica seu segundo livro do mesmo gênero, Indícios de Oiro. Os manuscritos que viriam compor esse volume haviam sido enviados a Fernando Pessoa antes de Sá-Carneiro suicidar-se num quarto do Hotel Nice, em Paris, e ficado a seu encargo para que os publicasse da maneira que lhe parecesse melhor. De fato, a maior parte dos poemas que compõem o livro, publicado também depois da morte de Pessoa, saiu em revistas e suplementos literários, por iniciativa de seu destinatário e de intermediários.

Como se sabe, Sá-Carneiro partiu para Paris em 1912, com o pretexto de cursar a Faculdade de Direito, atraído pela vida cultural e boêmia, sustentada pelas mesadas que o pai lhe remetia com intermitências. Durante esse período até a sua morte, o autor de $A$ confissão de Lúcio retorna a Lisboa em fins de 1913 e no início de 1915, quando ocorre a impressão dos dois números da revista Orpheu (em março e julho, respectivamente). Ali permanece até 15 de julho de 1915, data em que parte definitivamente a Paris.

Entre julho e setembro deste ano, Sá-Carneiro escreve constantemente a Pessoa, sentindo-se abandonado e suplicando-lhe cartas (se possível "relatórios"), que recebe em menor quantidade e extensão do que as que envia. A falta de notícias sobre as vendas de seu volume de contos recém-publicado, Céu em fogo (1915) e do segundo número da Orpheu, associada à falta de dinheiro, deixam-no num estado de grande ansiedade, por depender disso o seu destino na "Grande Capital". É ali que afirma desejar residir para sempre, mas "tudo menos Lisboa", conforme declara a Pessoa. É verdade que a capital portuguesa em muito se distanciava do cosmopolitismo parisiense, tão valorizado pela mentalidade modernista, mas o que Sá-Carneiro busca, de fato, é, com exceção de alguns poucos, a distância dos conhecidos, o isolamento. Gradativamente, a sua correspondência revela a solidão em que se encontra e o medo de enlouquecer. Em 13 de setembro, escreve a Pessoa uma "carta dolorosa", anunciando a necessidade de desistirem da Orpheu n.3, por falta de recursos de seu pai, que se encontra em Lourenço Marques (hoje, Maputo), capital da então colônia portuguesa de Moçambique.

No dia 18 de setembro, Sá-Carneiro envia a Pessoa uma carta em que transcreve o poema "Abrigo", núcleo desta leitura, e sobre o qual escreve o seguinte: "Peço-lhe a sua opinião sobre os dois poemas que hoje lhe envio. O 'Abrigo' é a sério. Acha bem aí o meu 
Paris? Não se esqueça de me dizer.” (SÁ-CARNEIRO, 2004, p. 291-293).

Interessa atentar para o comentário do autor, posto que documenta a concepção "a sério" do poema, bem como ele ter sido destinado, a exemplo de tantos outros poemas, a Fernando Pessoa, sem dúvida o intelectual português mais admirado pelo escritor e a cujo crivo submete este seu retrato parisiense. A pergunta "acha bem aí o meu Paris?" sugere o conhecimento prévio do amigo acerca da importância do tema para Sá-Carneiro, bem como a existência para si de uma Paris particular, invisível nos mapas e cartões postais. Embora não tenhamos a opinião declarada de Pessoa a seu respeito, a inclusão do poema num conjunto intitulado "Poemas de Paris", que abririam o número da Orpheu que não saiu do prelo, revela o assentimento do amigo. Não bastasse essa inclusão, antes de compor postumamente seu Indícios de oiro, o poema foi publicado por iniciativa de José Pacheco no primeiro número da revista Contemporânea (em maio de 1922), com o título "Do livro de versos deixado inédito por Mário de Sá-Carneiro 'Poemas de Paris"”, no lugar da denominação "Abrigo", e sucedendo $O$ Banqueiro Anarchista, de Pessoa. Esse breve histórico genético registra com boa probabilidade de acerto o apreço que o poema teve de seu autor e de seu primeiro leitor. É de se supor que o poeta o tenha produzido com base nas reminiscências de sua recente estada na terra natal. Esses versos melancólicos cantam a cidade luz com a nostalgia e o distanciamento de um exilado, de quem se projeta para longe dela.

\footnotetext{
Abrigo

Paris da minha ternura

Onde estava a minha Obra -

Minha Lua e minha Cobra,

Timbre da minha aventura.

Ó meu Paris, meu menino,

Meu inefável brinquedo...

- Paris do lindo segredo

Ausente no meu destino.

Regaço de namorada,

Meu enleio apetecido -

Meu vinho d'Oiro bebido

Por taça logo quebrada...

Minha febre e minha calma -

Ponte sobre o meu revés:

Consolo da viuvez

Sempre noiva da minh'Alma...

Ó fita benta de cor,

Compressa das minhas feridas...

- Ó minhas unhas polidas,

- Meu cristal de toucador...
} 
Meu eterno dia de anos,

Minha festa de veludo...

Paris: derradeiro escudo,

Silêncio dos meus enganos.

Milagroso carrossel

Em feira de fantasia -

Meu órgão de Barbaria,

Meu teatro de papel...

Minha cidade-figura, Minha cidade com rosto...

- Ai, meu acerado gosto,

Minha fruta mal madura...

Mancenilha e bem-me-quer,

Paris - meu lobo e amigo...

- Quisera dormir contigo,

Ser todo a tua mulher!...

Paris - setembro, 1915. (SÁ-CARNEIRO, 1995, p. 107-108).

O poema chama a atenção pelo seu nominalismo. Composto de nove quadras em redondilha maior e rimas emparelhadas, caracteriza-se pela ausência quase integral de verbos conjugados. Exceções somente ocorrem no segundo verso, ainda assim um verbo de ligação, e nos dois últimos versos. Estes completam a oração de sua abertura: "Paris, [...] / Quisera dormir contigo, / Ser todo a tua mulher!" Os três verbos, "estar", "querer" e "ser", ao expressarem localização e desejo, reforçam a imobilidade do texto, cuja composição se baseia numa sequência de metáforas relativas à cidade luz, enunciadas como vocativos. Essas metáforas glosam e reforçam o mote-título do poema.

Ao tratar, em conhecido artigo, do provincianismo que caracterizaria, a seu ver, a cultura portuguesa, Fernando Pessoa identificou a admiração de Sá-Carneiro por Paris como seu exemplo. É interessante pensar o poema a partir da seguinte consideração:

Se há característico que imediatamente distinga o provinciano, é a admiração pelos grandes meios. Um parisiense não admira Paris; gosta de Paris. Como há-de admirar aquilo que é parte dele? Ninguém se admira a si mesmo, salvo um paranóico com o delírio das grandezas. Recordo-me de que uma vez, nos tempos do 'Orpheu', disse a Mário de Sá-Carneiro: "V. é europeu e civilizado, salvo em uma coisa, e nessa V. é vítima da educação portuguesa. V. admira Paris, admira as grandes cidades. Se V. tivesse sido educado no estrangeiro, e sob o influxo de uma grande cultura europeia, como eu, não daria pelas grandes cidades. Estavam todas dentro de si”. (PESSOA, 1980, p. 159).

Os "tempos de Orpheu", conforme se refere Pessoa, são também os tempos de "Abrigo". O espirituoso diagnóstico parece se ajustar melhor, no entanto, aos momentos da obra de Sá-Carneiro que enaltecem a confusa contemporaneidade e a atividade febril do centro urbano. Já neste poema, a referida imobilidade de expressão caracteriza um lugar 
estático que muito pouco se mostra em sua realidade cosmopolita, ao contrário, por exemplo, da Lisboa pictórica de Cesário Verde, a um só tempo dinâmica e vertiginosa, viva e degradante. Aqui, a Paris de Sá-Carneiro não se constrói pelos sentidos, mas pelos afetos. É, justamente, aquilo que Pessoa afirma que seria caso tivesse o autor uma educação estrangeira: um espaço íntimo, uma cidade dentro de si, não o lugar geográfico em que habita, mas acentuadamente subjetivo e ambíguo, refeito, mesmo idealizado, a partir de um interior que se projeta para fora. Por esse motivo, "Abrigo" parece revelar o influxo dessa concepção de Pessoa na concepção poética do amigo.

Note-se que a expressão "meu menino", típica de uma voz maternal, destina-se a designar Paris (aliás, masculino, em francês) segundo uma ternura que já vem referida no primeiro verso: "Paris da minha ternura". O eu lírico busca, com expressão tão acolhedora, um lenitivo à sua orfandade, através do abrigo que intitula o poema, dirigindo-se à cidade como se o fizesse a si próprio. Esse anseio maternal tende a estender-se por um desejo de identificação com o espaço exterior, por sua conversão em porto-seguro. Idealizada em resposta às mais íntimas faltas, Paris é já "inefável brinquedo", "feira de fantasia", "teatro de papel", imagens que carregam consigo o lúdico e o imaginativo. Esse resgate do universo infantil pela evocação da cidade transforma-a em espaço anímico, moldado na circunstância em que é mencionada. O poeta vê-se, afinal, em menino, num lugar de "aventura" e "fantasia", em que o "regaço da namorada" acolhe como o "colo materno".

Sá-Carneiro evoca Paris reavivando a infância (normalmente referida pela crítica como perdida aos dois anos, com a morte de sua mãe). É só porque se trata, afinal, de uma cidade simbólica, que Paris pode ser evocada, não de outra cidade, mas da própria Paris (local de escrita do poema) - por ser um lugar em que não se está, a não ser pela imaginação. A representação idealizada de um espaço e um tempo edênicos é reparadora, nesse sentido, de um luto primordial, de uma perda que, na vida real, não pode ser restituída. Trata-se aqui de um forte desejo de restituição que se transfigura na utilização obsessiva de pronomes possessivos em todas as estrofes do poema, mais precisamente em 26 versos (em muitos deles, mais de uma vez) de um total de 36.

A propósito de um poema em que a nostalgia exerce papel tão fundamental, cabe lembrar a reflexão de Linda Hutcheon (2000), segundo a qual a nostalgia tem maior proximidade com o presente do que com o passado. A seu ver, o passado idealizado como momento puro, belo e harmonioso é construído como resposta ao presente manchado e caótico. A nostalgia nasce, assim, de uma insatisfação, e dela se projeta em traços de 
memória, como uma saudade da vida que poderia ter sido e que não foi, pelo verso lapidar de Manuel Bandeira. Mais do que a saudade, portanto, que se esgota na presença da pessoa ou do objeto saudoso, a nostalgia se reporta a uma eterna ausência, a uma impossibilidade que só pode ser revertida em forma artística. É nesse sentido que Hutcheon a designa como creative sorrow, uma resposta emocional que a nostalgia fornece à privação e a radica num tempo duplicado, na inversão cronológica de um passado nascido do presente.

A propósito dessa conversão do psicológico em literário lembre-se o procedimento de leitura adotado por Fernando Cabral Martins em seu principal estudo da obra de SáCarneiro. Partindo da premissa de que o eu elocutório nunca coincide completamente com o eu empírico, o crítico procura ler, na segunda parte de sua tese (especificamente o capítulo “Cartas”, p. 82-121), a correspondência de Sá-Carneiro a Fernando Pessoa como parte de sua obra, isto é, como exercício de um gênero de escrita que serve ao propósito modernista de ficcionalizar o real, a fim de superar a abordagem predominantemente biográfica que se tem feito de si. Essa sua estratégia radical procura resgatar a dimensão propriamente artística de poemas normalmente abordados como biografemas e de uma obra cujos "comentários críticos produzidos ao longo dos anos tem sido a conjectura da sua personalidade, mais do que a sua arte”. (MARTINS, 1994, p. 13).

Cabe notar que ficcionalizar a realidade não significa, no que concerne à obra de SáCarneiro, adulterá-la completamente, inventá-la do zero, e sim conferir-lhe contornos, matizes e ênfases mais subjetivos; numa palavra, significa dramatizá-la. As associações com o real, se por um lado não devem desviar, numa leitura que se pretenda literária, a ênfase sobre a linguagem, por outro, não podem ser simplesmente ignoradas, sob o risco de uma defasagem interpretativa. Mesmo um hipotético leitor desinformado e sensível, isto é, apto a uma leitura míope para tudo o que não seja literário, tratará como ficcional a matéria documental presente nas cartas e nos diários, do que resultará sua intertextualidade com os poemas. Assim, se voltarmos a "Abrigo", em contraposição ao desejo de posse, manifesto, conforme anotamos, na obsessão pelos possessivos, a passagem "Meu vinho d'Oiro bebido / Por taça logo quebrada..." sugere uma dupla associação, tanto entre "vinho d'Oiro" e o leite materno, quanto entre a "taça logo quebrada" e a morte precoce da mãe, de tal modo a sintetizar dolorosamente - digamos, dramaticamente - uma perda irreparável.

Tanto ao presente, como ao futuro sem esperanças, opõe-se o passado idealizado no poema: "- Paris do lindo segredo / Ausente no meu destino." Não apenas "o lindo segredo", mas a "Paris do lindo segredo" está ausente do passado do eu lírico. Trata-se da dissolução da 
cidade de faz de conta que lhe serve de "consolo", à qual teme não poder voltar, ou mesmo da nuvem cinza que paira sobre a cabeça (os escritos) de um poeta às voltas com a ideia de dar cabo de tudo. O futuro sem Paris, sem, portanto, as reminiscências de uma infância sonhada que talvez não fossem possíveis na terra natal que acabara de deixar, mas para onde, sem o custeio do pai, inevitavelmente teria que regressar - é um tempo sem "compressa" para as "feridas". Um tempo destituído de "consolo" para a realidade.

Sucede que, se a relação com a própria infância se faz da dualidade entre o que é sonhado e o que foi vivido, a relação do poeta com Paris não é menos ambígua. Embora o aproxime da infância, Paris é também um bem distante, ao mesmo tempo sua "febre" e sua "calma", "Mancenilha e bem-me-quer", "lobo e amigo", sua "Lua" e sua "Cobra". Na carta a Pessoa, em que Sá-Carneiro transcreve "Abrigo", depois de comentar o poema "Serradura" (também ali transcrito), termina com a seguinte pergunta, referente ao poema aqui analisado: “Como se escreve 'Mansanilha'? Não se esqueça de me dizer. Não tenho a certeza se é mansanilha ou massanilha..." (SÁ-CARNEIRO, 2004, p. 292). Em contraste com a delicadeza do crisântemo ou bem-me-quer, a mancenilha (em espanhol, manzanilla de la muerte, por seus frutos lembrarem pequenas maçãs) é uma árvore da qual se extrai um suco altamente tóxico. Uma árvore mortífera, afinal.

Essa construção dual é aspecto que merece atenção no poema. Por um lado, se o Abrigo que acolhe é a recuperação da infância, e, portanto, de uma maternidade perdida, por outro lado, a ele o sujeito poético sonha entregar-se incestuosamente ("Ser todo a tua mulher!...”), um pouco à maneira com que Álvaro de Campos, na "Ode Marítima”, em seu êxtase no cais, deseja estar com os piratas evocados na carnagem e na pilhagem, e ser-lhes "as fêmeas" e "as vítimas": "Estar convosco na carnagem, na pilhagem! /Estar orquestrado convosco na sinfonia dos saques! / Ah, não sei quê, não sei quanto queria eu ser de vós! Não era só ser-vos a fêmea, ser-vos as fêmeas, ser-vos as vítimas, Ser-vos as vítimas - homens, mulheres, crianças, navios -" (PESSOA, 1965, p. 236) Como manifestação mais exuberante do sensacionismo, trata-se, em Campos, de um desejo de entrega tanto erótica quanto anímica: "A minha feminilidade que vos acompanha", afirma Campos, "é ser as vossas almas!" (PESSOA, 1965, p. 326). Vem a propósito lembrar que, em "O homem dos sonhos", conto do volume Céu em fogo, o narrador, estudante falido de Medicina, reencontra, num restaurante gorduroso de Paris, um homem misterioso e extravagante, que sempre almoçava ali, e com quem finalmente passa a conversar. Uma das "ideias bizarras" desse estrangeiro de resto, tema fulcral em A confissão de Lúcio - e que se relaciona com a ideia contida no 
verso há pouco citado de Sá-Carneiro, manifesta-se na seguinte pergunta: "A propósito: conhece alguma coisa mais desoladora do que isto de só haver dois sexos?" (SÁCARNEIRO, 2010, p. 480).

Em Sá-Carneiro, esse mesmo abrigo encerra também seus "males", num sentido que é preciso indicar. É que a entrega total já não é mais a de um poeta-criança em sonho, e sim de um eu lírico feminizado que se conduz para o prazer e a autoanulação, faces de uma mesma moeda. Esse sentir ao extremo é típico de Campos, o heterônimo mais referido por SáCarneiro, pela admiração e identificação que sente por ele, em sua correspondência com Pessoa. Na mesma "Ode Marítima”, lemos, imediatamente após o clímax do poema, "Senti demais para poder continuar a sentir". Alguma coisa se rompe. Essa modalidade do sensacionismo, por levar o sujeito sensitivo ao extremo, o conduz à autoanulação. Na carta de despedida a Fernando Pessoa (31-03-1916), aquela na qual Sá-Carneiro anuncia que tomaria uma forte dose de estricnina e desapareceria do mundo, temos, associada a essa vontade de morte, o testemunho do que, em "Passagem das horas", é referido como "Sentir tudo de todas as maneiras, / Viver tudo de todos os lados, / Ser a mesma coisa de todos os modos possíveis ao mesmo tempo, / Realizar em si toda a humanidade de todos os momentos / Num só momento difuso, profuso, completo e longínquo.” (PESSOA, 1965, p. 344). Na referida carta, lê-se: "Vivo há quinze dias uma vida como sempre sonhei: tive tudo durante eles: realizada a parte sexual, enfim, da minha obra - vivido o histerismo do seu ópio, as luas zebradas, os mosqueiros roxos da sua Ilusão." (SÁ-CARNEIRO, 2010, p. 373-374) Paris representa, portanto, tanto o nascimento quanto a morte, símbolo dum passado edênico e terminal das ilusões de um "eu" inadaptado.

Dentre as expressões citadas que ilustram essa dúplice ideia, a que talvez esteja mais carregada de referências seja a enunciada logo no terceiro verso do poema: "Minha Lua e minha Cobra". Essas duas imagens, em regime de oposição, marcaram muito fortemente a poesia de António Nobre, de quem Sá-Carneiro realizou, inclusive, um poema-retrato, do mesmo Indícios de Oiro, intitulado "Anto" (SÁ-CARNEIRO, 1995, p. 94):

\footnotetext{
ANTO

Caprichos de lilás, febres esguias, Enlevos de Ópio - Íris-abandono... Saudades de luar, timbre de Outono, Cristal de essências langues, fugidias...

O pajem débil das ternuras de cetim,

O friorento das carícias magoadas;

O príncipe das Ilhas transtornadas -
} 
Esta homenagem prioriza um aspecto, ainda que presente na obra de Nobre, menos característico dela. É curioso notar como, num poema tão nobiliárquico, o autor refere-se a um António Nobre diverso daquele que entrevemos em SÓ. Em certo sentido, Nobre é aqui referenciado por uma poética à qual deu as costas. Note-se, por exemplo, o contraponto entre a imagem nobreana da "Torre de Leite" com a "Torre de Marfim", em sua homenagem. O poema parece, afinal, a projeção de uma poética sobre outra. É possível arriscar dizer que o poema do autor de Orpheu dialoga diretamente com uma passagem da primeira parte de "Males de Anto", de Nobre, intitulada "A ares numa aldeia", em que se lê: "E vencer pela Pátria! E ser Conde da Terra / E do Mar! El-Rei! Ser Senhor feudal do Mundo!" (NOBRE, 2000, p. 221-234) Passagem, afinal, muito afim com os dois últimos versos do poema de SáCarneiro: "O príncipe das Ilhas transtornadas - / Senhor feudal das Tôrres de marfim..." Eis, no retrato que Sá-Carneiro fez de Nobre, uma caracterização perfeita de si mesmo. Ou, para lançarmos mão da expressão pessoana, de sua ternura introvertida.

Assim como sucedeu com Sá-Carneiro, António Nobre perdeu a mãe muito cedo e mudou-se para Paris, com o mesmo motivo acadêmico. Se é verdade que Nobre chegou a licenciar-se em Ciências Políticas pela mesma Sorbonne, em 1894, assim como ocorre com o poeta órphico, para quem estudar na França não passava de um pretexto, foi a atividade poética o que sempre o ocupou. Nobre também morreu cedo e solteiro, aos 33 anos, e, como se sucedeu com Sá-Carneiro, passou a curta vida sustentado pela família, devido à tuberculose, contra a qual lutou desesperadamente. (CASTILHO, 1979). Ambos cultivaram a verve excêntrica, expressa com acentuado individualismo em suas obras. Essas importantes semelhanças não apagam, claro está, as diferenças de valores e os caminhos diversos que suas poesias tomaram, mas ganham em sentido quando consideramos a influência de Nobre sobre seu sucessor modernista. Vem a propósito lembrarmos o seguinte poema (NOBRE, 2000, p. 33):

MEMÓRIA

Aquele que partiu no brigue Boa Nova E na barca Oliveira, anos depois, voltou; Aquele santo (que é velhinho e lá corcova) Uma vez, uma vez, linda menina amou: Tempos depois, por uma certa lua-nova, Nasci eu... O velhinho ainda cá ficou, Mas ela disse: - "Vou, ali adiante, à Cova, António, e volto já...” E ainda não voltou! 


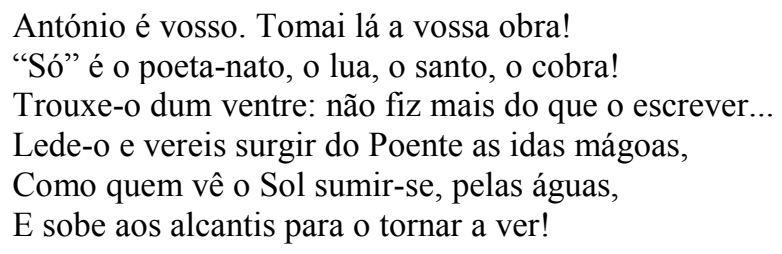

Note-se a semelhança entre os versos de Sá-Carneiro "Paris da minha ternura / Onde estava a minha Obra - / Minha Lua e minha Cobra," e os de Nobre, no poema-síntese de sua obra: “António é vosso. Tomai lá a vossa obra! / 'Só' é o poeta-nato, o lua, o santo, o cobra!" Enquanto se estabelece um claro jogo de oposições em "Abrigo", entre dois mistérios, um positivo, o outro negativo: a "lua", alta e luminosa, e a "cobra", rastejante e peçonhenta, em "Memória" nos deparamos com um complexo universo simbólico. Ali, o contraste se estabelece entre "santo" e "cobra", como metáforas do bem e do mal, conviventes numa mesma personalidade, designada como sendo a de um "poeta-nato". Ser poeta desde o nascimento é estar predestinado ao isolamento: o verso "“Só' é o poeta-nato...” não exclui, mesmo sugere, a leitura inversa: o poeta nato é só. A "lua” não simboliza apenas o bem; ela é, das três imagens, aquela que apresenta um sentido mutante, e não fixo, dependente de suas diferentes fases. Em sua altitude, condensa, por isso, as duas outras imagens, de "santo" e "cobra". Reforça essa leitura a retomada dessa mesma imagem, de modo mais explícito, na segunda versão do poema (considerada a definitiva), em que se lê: "E assim se criou um anjo, o Diabo, o lua." "SÓ” é, assim, anjo, Diabo, e os dois ao mesmo tempo.

Se voltarmos ao poema de Sá-Carneiro, veremos que o uso de imagens análogas às de Nobre não se dirige ao eu poético, como acontece em "Memória", mas à "Obra", que, por sua vez, expressa a duplicidade do eu que escreve. O eu lírico explicita que essa Obra "estava" em Paris, que é evocada como espaço mítico e, como vimos, local em que o poeta escreveu a maior parte de seus textos. Essa "Obra" - metonimicamente o poema "Abrigo" ao expressar as duas faces do sujeito a que se refere, expressa também as duas faces de Paris. Lembremos uma das maneiras como se descreve a cidade no poema: "Minha cidade-pura, / Minha cidade com rosto...”. Antropomorfizada, também Paris é objeto de uma percepção particular (afinal, não terá seu rosto as feições de sua própria face?), filtrada pelas idiossincrasias do sujeito poético e representada paradoxalmente.

Paris é um espaço-chave nas poesias de Sá-Carneiro e Nobre, não apenas por boa parte de seus poemas ter sido produzida ali, mas como realidade simbólica. No entanto, notese a significativa diferença de perspectiva dos poetas com relação à cidade. Paris representa o exílio de "António", saudoso da pátria querida, em especial do Portugal aldeão e tradicional, representado pelas figuras prosaicas de Tia Delfina, Zé do Telhado e o cão Farrusca, na 
primeira voz do poema que leva o nome do poeta. (NOBRE, 2000, p. 39) Esse afastamento de si entrevê-se nas romanceadas palavras de Guilherme de Castilho, biógrafo do autor, na abertura do capítulo intitulado "A Caminho do Exílio":

Tejo abaixo, em direção ao mar, vai descendo um vaporzinho ligeiro que deixa atrás de si um penacho muito tênue de fumo acinzentado. O Sol está prestes a desaparecer no horizonte e já as colinas da Outra Banda se vão cobrindo de tons violáceos do entardecer. A alguns metros de distância, passa por ele um paquete cheio de luzes que dá a impressão duma pequena aldeia flutuante, com os seus casebres iluminados. (CASTILHO, 1979, p. 97)

Os poemas de Nobre ensejam essa descrição romanceada sobre o martírio lento, no ritmo do vapor ou da fumaça que dissipa, de um jovem poeta abandonando a si próprio rumo ao desconhecido. Já esse tom melancólico que Castilho imprime à partida de Lisboa não se ajustaria à viagem de Sá-Carneiro. Em "Abrigo", a saudade da infầncia não é representada pelo desejo de voltar à cidade natal, muito menos de resgatar tradições. O seu passado é projetado idealmente sobre o espaço mítico que cria para Paris, como uma espécie de ponte, de consolo imaginário.

Essa cidade de sonho, profusamente retratada em sua correspondência e literatura, contrasta com uma realidade grave e urgente. Quando "Abrigo" foi escrito, a Alemanha havia, há cerca de um ano, declarado guerra à França e bombardeado a cidade de Lunéville. Batalhas haviam ocorrido em território francês, como as de Champagne e Soissons, e a capital sido transferida para Bordeaux. Os escritos de Sá-Carneiro não revelam, entretanto, preocupação com o estado de guerra. Como se o poeta vivesse uma realidade à parte da história, fictícia, volta-se para si, preocupa-se, sim, com o próprio equilíbrio mental, o dinheiro que não lhe basta, o silêncio do amigo Pessoa e sua opinião sobre os poemas que lhe envia por correspondência. Um mundo inventado é o seu. Paris começaria a ser bombardeada em janeiro de 1916, e isso parece não o abalar. Em março daquele ano, começa a anunciar nas cartas a Pessoa que irá suicidar-se. O seu tormento psíquico nada deve a rifles ou canhões.

$\mathrm{O}$ enfraquecimento da indústria francesa, devido à invasão de territórios extrativistas pelos alemães, a atmosfera de tensão e o crescente esvaziamento dos espaços públicos, por evidente que fossem, atingiam a sensibilidade do poeta, mas como o que se passa, não propriamente consigo, mas ao derredor. Em carta a Pessoa, enviada cerca de dois meses antes da escrita de "Abrigo", o poeta descreve-lhe Paris como uma "maravilha" que, no entanto, não se encontra "em plena paz". Sua febre cosmopolita está "esmaecida", sua energia se "atenuou". A antiga Paris, como as cidades de sua "ânsia", "farfalhantes de acção", é agora uma cidade velada, como se os volantes que movem as suas engrenagens girassem mais 
lentamente. Não há menção direta à guerra, o poeta parece mesmo desconsiderá-la ao falar na sua "enigmática e perturbadora [...] realidade diminuída": "Pois em resumo assim é: Paris, diminuído em grandeza, desconhecidamente ungiu-se de oculto, diluiu-se em incerto” [...] "Dir-se-ia uma cidade furtiva, em suma, meu querido Amigo: uma cidade fora do espaço e do tempo: existindo às escuras". Todo o texto da carta denuncia uma perspectiva a-histórica, "fora do espaço e do tempo", tal como o escritor descreve a partir de um estado de espírito melancólico e de uma performance literária. Tanto é verdade que, no seu arremate, o poeta pergunta a Pessoa se o texto da carta, uma vez transformado em crônica, se ajustaria ao n. 3 da Orpheu. (SÁ-CARNEIRO, 2004, p. 247-249).

O procedimento literário adotado por Sá-Carneiro é também um analgésico, uma vez que a teatralização do espaço geográfico, transformado em espaço literário, serve-lhe como um neutralizador, ainda que imperfeito na forma de um ambíguo e algo suspeito "abrigo", de um exílio profundo e latente, cujas consequências deixariam definitivamente de se abater sobre si no dia 26 de abril de 1916. Essa transferência de um afeto perdido para a cidade idolatrada - que não lhe devolve mais do que, afinal, ele próprio projeta sobre si -, fica nítida quando o poeta viaja a Barcelona, cidade por que não alimenta especial empatia, e de lá escreve a Pessoa: "Paris enfim meu amigo, era as mãos louras, a ternura enlevada que não teve nunca a minha vida. E hoje bateram-lhe, fecharam-lhe em casa. Daí o meu sofrimento magoado, amoroso - é verdade: amoroso - ao relembrá-lo...” (SÁ-CARNEIRO, 2004, p. 214).

Se não é propriamente a cidade real, mas a cidade imaginada, o alvo dos afetos do poeta, Sá-Carneiro se apercebe de que não é preciso estar em Paris para tê-la consigo. Ao contrário, sua consciência desperta para a necessidade de, ao menos por vezes, estar justamente longe dela para possuí-la em seu esplendor. O poeta admite, afinal, que essa sua Paris é um espaço de linguagem, produto de sua nostalgia imaginativa:

\footnotetext{
Eu amo incomparavelmente mais Paris, eu vejo-a bem mais nitidamente e compreendo-a em bem maior lucidez longe dela, por Lisboa, do que aqui, nos seus boulevards onde até, confesso-lhe, meu Amigo, por vezes eu lhe sou infiel e, em vislumbre, me lembro até da sua desnecessidade para a minha alma, para a minha emoção... (SÁ-CARNEIRO, 2004, p. 186-187)
}

A Paris em que Sá-Carneiro viveu, espaço comum de abrigo e exílio, irrealizou-a em linguagem, desfazendo sua historicidade e sonhando-a para si, numa intimidade transfiguradora cuja descrição mais iluminada encontramos no desfecho de seu conto " $\mathrm{O}$ Homem dos Sonhos". Eis o título que, ao retratar um estrangeiro de gestos extravagantes e ideias bizarras, identifica com precisão esse nosso excêntrico sonhador: 
E eis como eu pude entrever o infinito. O homem estranho sonhava a vida, vivia o sonho. Nós vivemos o que existe; as coisas belas, só temos força para as sonhar. Enquanto que ele não. Ele derrubara a realidade, condenando-a ao sonho. E vivia o irreal. (SÁ-CARNEIRO, 2010, p. 477)

\section{Referências}

CASTILHO, Guilherme de. Vida e obra de António Nobre. 3. ed. Lisboa: Livraria Bertrand, 1979.

HUTCHEON, Linda. Irony, Nostalgia, and the Postmodern. In: VERLIET, Raymond; ESTOR, Annemarie (Ed.). Methods for the Study of Literature as Cultural Memory. Atlanta: Rodopi, 2000, p. 189-207.

MARTINS, Fernando Cabral. O Modernismo em Mário de Sá-Carneiro. Lisboa: Editorial Estampa, 1994.

NOBRE, António. Só. Pref. de Mário Cláudio. Lisboa: Publicações Dom Quixote, 2000.

PESSOA, Fernando. Correspondência: 1923-1935. Lisboa: Assírio \& Alvim, 1999. Ed. Manuela Parreira da Silva. 1965.

Obra poética. Org., intro. e notas de Maria Aliete Galhoz. Rio de Janeiro: Aguilar,

O Provincianismo português (1928). In: . Textos de Crítica e de Intervenção. Lisboa: Ática, 1980.

SÁ-CARNEIRO, Mário de. Correspondência com Fernando Pessoa. São Paulo: Companhia das Letras, 2004. Ed. Teresa Sobral Cunha. 1995.

. Obra completa. Intro. e Org. Alexei Bueno. Rio de Janeiro: Editora Nova Aguilar, Verso e prosa. Ed. Fernando Cabral Martins. Lisboa: Assírio \& Alvim, 2010.

SIMÕES, João Gaspar. O mistério da poesia: ensaios de interpretação da génese poética. Coimbra: Imprensa da Universidade, 1931.

[Recebido em 19 de maio de 2016 e aceito para publicação em 18 de setembro de 2016]

\section{Sá-Carneiro's shelter and exile}

Abstract: Paris is a key space in Mário de Sá-Carneiro poetry, not only for most of his poems have been produced there, but as a symbolic reality. This paper aims to reflect on the symbolic role played by Paris in the work of Sá-Carneiro, based on the analysis of the poem "Shelter" (1915), its comparative approach with the poem "Memory", by other Portuguese poet António Nobre, and the correspondence with his friend and colleague generation 
Fernando Pessoa. Transfigured by language, Paris is here focused both as an identification and otherness space: at the same time shelter to affects repressed in a lost past and internal exile in a imaginary present. This dream city, lavishly portrayed both in correspondence and in the author's literature, contrasts with a serious and urgent historical reality. The poet admits, after all, that its Paris is a language space, product of his imagination nostalgia. Keywords: Mário de Sá-Carneiro. António Nobre. Exile. Paris.

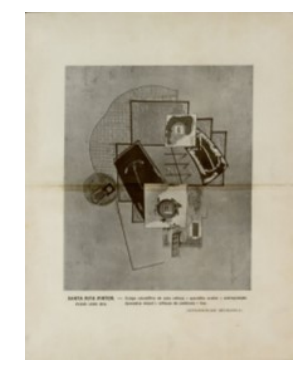

